\title{
Comparison of Nutrient Intake in Lao PDR by the Korean CAN-Pro and Thailand INMUCAL Analysis Programs
}

\author{
Yeseung Jeong ${ }^{1}$, Kyungock $\mathrm{Yi}^{2}$, Visanou Hansana ${ }^{3}$, Ji-Myung Kim${ }^{4}$, and Yuri Kim ${ }^{1}$ \\ ${ }^{1}$ Department of Nutritional Science and Food Management, and ${ }^{2}$ Division of Kinesiology \& Sports Studies, \\ College of Science and Industry Convergence, Ewha Womans University Graduate Program in System Health Science and Engineering, \\ Ewha Womans University, Seoul 03760, Korea \\ ${ }^{3}$ Institute of Research and Education Development, University of Health Sciences, Vientiane 7444, Lao People's Democratic Republic \\ ${ }^{4}$ Food and Nutrition Major, Division of Food Science and Culinary Arts, Shinhan University, Gyeonggi 11644, Korea
}

\begin{abstract}
A computer-based nutritional analysis program can help to identify the nutritional status of people and provide information for nutritional counseling, nutrition education, diet planning, and menu development. Although computer-based nutritional analysis has been conducted since the 1960s in developed countries, in developing countries nutritional analysis programs either do not exist or need improving. This study tests two analysis programs developed by different countries to compare the nutrition status data calculated by two different analysts to highlight the importance of developing an appropriate nutrition analysis tool. An interview-administered 24-h dietary recall method was conducted with 100 adults aged 40 59 years in Vientiane, Laos. Analysts from Korea and Laos, respectively, calculated nutrient intake using the Institute of Nutrition, Mahidol University CALculation (INMUCAL) nutritional analysis program (Bangkok, Thailand). Nutrient intake was also compared using two different analysis tools, INMUCAL and computer aided nutritional analysis program (CAN-Pro) 5.0 software (Seoul, Korea). The average nutrient intake calculated by the different analysts using INMUCAL were not significantly different. Furthermore, macronutrient intake calculated by CAN-Pro 5.0 and INMUCAL did not significantly differ, aside for intake of iron, thiamin, and vitamin C. Nutrient intake calculated by one analysis program differed from those calculated by a different program in Laos. Therefore, it is necessary to develop an appropriate nutritional analysis program that reflects the diet behavior and food culture in Laos and to understand the nutritional status of Laotians.
\end{abstract}

Keywords: CAN-Pro, INMUCAL, Lao PDR, nutrients intake, nutritional analysis program

\section{INTRODUCTION}

Societies are dramatically changing because of globalization, urbanization, and rapid economic growth. These changes have greater social impact in developing countries than in developed countries. Urbanization, global integration, and economic and income growth in developing Asian countries have led to new dietary habits and lifestyle changes (Pingali, 2007). The evolving dietary habits are characteristic of more westernized food consumption, with strong preferences for meat, dairy products, simple sugars, and processed foods. Moreover, rapid lifestyle changes, such as alcohol consumption, smoking, and lack of exercise, has been exhibited in developing countries because of a modernized society and urban lifestyle. This lifestyle transition is a risk factor for chronic diseases and non-communicable diseases (NCD), which have recently increased in prevalence in these countries (Low et al., 2015). Indeed, the increasing global threat of chronic diseases, such as cardiovascular diseases, cancer, and diabetes, is well recognized. The World Health Organization (WHO) reported that $48 \%$ of the deaths of Laos in 2014 were caused by chronic diseases, such as cardiovascular diseases $(22 \%)$, cancer $(11 \%)$, respiratory diseases $(5 \%)$, diabetes $(2 \%)$, and other NCDs $(8 \%)$ (WHO, 2014).

One of the main causes of chronic diseases is a poor diet (Schoendorfer et al., 2017). The importance of nutritional education and counseling is emphasized by the substantial effect exerted by dietary habits on the prevention and treatment of chronic diseases (Holben and Marshall, 2017). A previous study reported that residents 
of Laos have limited knowledge of food- and nutrition-related determinants of NCDs. Laotians generally consume staple foods, including steamed glutinous rice and fish sauce without side dishes (unpublished data). This lack of nutrition knowledge and unbalanced food intake may increase NCDs in Laos.

Previously, we reported eating habits of Laotians. We showed that Laotians eat three meals daily and consume meat and fish, but consume relatively less milk and dairy products daily. In particular, most Laotians consume fruit less than twice a week. Laotians are increasingly consuming an unhealthy Western diet, which is one of main causes of increasing NCD development in Lao PDR (Kim et al., 2016).

Nutritional intake can be assessed by direct methods, including a duplicate diet approach (Bramwell et al., 2017). However, duplicate diet sample collection methods are impractical for large-population epidemiological studies (Shim et al., 2017). Therefore, nutritional intake is more commonly evaluated by computerized nutritional analysis programs. Computer-based nutritional analysis has been conducted since the 1960s in developed countries across diverse fields, including nutritional counseling, nutrition education, clinical nutrition management, and diet planning. The software for diet assessment is developed for ease of use by both the general public and nutrition specialists, with the aim of improving public health and for disease therapy (Han and Rhee, 1993). These computerized diet assessment programs enable collection and quantification of information, and help save time when analyzing the data. Previously, Vaask et al. (2004) highlighted the importance of developing comparable national databases for specific regions to allow accurate interpretation of diets in different countries. In addition, by developing computerized nutritional programs, people can easily use the programs to recognize the importance of diet, helping them plan appropriate dietary regimens. Therefore, development of computerized nutritional analysis systems in individual countries is considered to be important for public nutrition. However, few developing countries have their own nutritional analysis programs.

Institute of Nutrition, Mahidol University CALculation (INMUCAL) is a program developed by the Institute of Nutrition at Mahidol University (Bangkok, Thailand) and includes a nutritional database of foods typically consumed in Thailand (Supasyndh et al., 2009). Computer aided nutritional analysis program (CAN-Pro) is a welldeveloped software program for nutrient intake analysis, and is the most widely used program for nutrition counseling and education in Korea. CAN-Pro makes it relatively easy to convert food approximations to weight by selecting the amount of food, allowing the nutrient content of the consumed food to be easily calculated. In or- der to standardize nutrient assessment, a database was established for commonly consumed Korean foods based on representative recipes. The program also provides a graphical representation for nutrient intake, the ratio of caloric intake from macronutrients, the ratio of plant nutrient intake, and the contribution rate of nutrients per meal.

Appropriate national food composition tables (FCT) and nutritional assessment programs do not currently exist in Laos. This lack of analytical tools and databases for nutritional analysis may make it difficult to perform appropriate nutrition education in Laos. In addition, the results of nutritional assessment using unstandardized programs may not be consistent depending on the analysts and analysis programs used, because dietary habits and food cultures differ by race and ethnicity. Therefore, this study had three main objectives: 1) to compare nutrient intake calculated by different analysts using the INMUCAL analysis program; 2) to compare nutrient intake analyzed by two different programs, INMUCAL and CANPro; 3 ) to propose the necessity for developing a nutrient analysis program in Laos.

\section{MATERIALS AND METHODS}

\section{Study subjects and software}

During May June 2015, 25 cities and 25 villages in Lao PDR were arbitrarily selected from two urban areas (Vientiane Capital-Chanthabuly and Xaysetha) and two rural areas (Vientiane Province-Phonhong and Thoulakhom). A total of 100 adults (50 men and 50 women) aged 40 $\sim 59$ years were randomly selected, which included two adults from each city and village. The nutritional analysis programs used were INMUCAL V.3 (Mahidol University, Bangkok, Thailand) and CAN-Pro 5.0 (Web version; The Korean Nutrition Society, Seoul, Korea).

\section{First analysis (different analysts)}

To identify differences in nutrient intake according to different analysts, two analysts analyzed the same subjects using the same INMUCAL V.3 program. After excluding subjects who consumed $\leq 500$ and $\geq 5,000 \mathrm{kcal}, 82 \mathrm{sub}-$ jects (48 men and 34 women) were selected for the nutrient intake analysis by the different analysts.

\section{Second analysis (different programs)}

To identify differences in nutrient intake according to different analysis programs, the same analysts used INMUCAL V.3 and CAN-Pro 5.0. To avoid errors of extreme food intake, subjects who consumed $\leq 500$ and $\geq 5,000$ kcal energy, as analyzed by each program, were excluded. If a subject was excluded by these criteria from one data program, the subject was also excluded from the other 
program. Finally, 79 subjects (42 men and 37 women) were selected for comparative analysis of nutrient intake by the different analysis programs.

This study was approved by the Institutional Review Board of Ewha Womans University (No. 89-12) and the Ministry of Health, National Institute of Public Health, National Ethics Committee for Health Research in Laos (069 NIOPH/NECHR).

\section{Dietary assessment}

Collection of energy and nutrients were collected by a single 24-h recall. During the face-to-face interview with trained researchers, food models, and pictures of foods and dishes were used to help participants assess standard food portion sizes. Questions about snacks, drinks, and supplements were also asked. Interviews were conducted in the Lao language and were translated into English by a researcher who spoke both languages. Food intake was converted to nutrient consumption using both INMUCAL V.3 program and CAN-Pro 5.0.

The INMUCAL-Nutrient software program includes more than 30 kinds of food and 15 types of nutrients. This program converts raw food intake to nutrients and the percentage of the Thai dietary reference intake (DRI) (Klunklin and Channoonmuang, 2006). INMUCAL can be used to analyze and calculate personal nutrient intake per day (Banjong et al., 2003; Jeharsae et al., 2011). The program was developed to calculate nutrient intake from food for diet planning, evaluation of nutritional status, and study of food and nutrition in Thailand (Institute of Nutrition, Mahidol University, 2013). It is composed of a nutrient database reflecting most complete and modern Thai food, searchable by food code and data input. In addition, INMUCAL considers cooking methods. For example, if frying is selected as the cooking method, the oil weight is automatically included. Similar to CAN Pro, INMUCAL provides nutritional information for each subject based on the DRI for Thai. This program has been continuously developed for 20 years by the Institute of Nutrition, Mahidol University, and contains food items similar to Lao foods. Thus, this program is suitable for analyzing nutrient intake of Laotians.

CAN-Pro 5.0 is a Korean nutritional analysis program developed and distributed by the KNS. The first version (CAN-Pro 1.0) was released in 1998, followed by five subsequent versions. CAN-Pro has gradually expanded the content of its food and nutrient database. Based on data from the FCT of the KNS (2009) and Rural Development Administration (2006), food databases contain basic nutrients, such as carbohydrates, fatty acids, and amino acids. Databases have been modified and updated, by adding missing values of the existing 24 nutrients and adding micronutrients. CAN-Pro, which has been reviewed and validated by nutrition experts, consists of 48 basic nutrients, 39 fatty acids, and 21 amino acids, and contains more than 1,700 types of dishes and 3,926 foods. Currently, it is the most widely used research tool for dietary assessment in the food and nutrition field of South Korea. CAN-Pro is used as a nutritional management tool for evaluating the nutritional statuses of individuals or groups to improve the health of the general public. Proper assessment of nutritional adequacy of food intake helps to maintain optimum health. In order to calculate the nutrient content of consumed food, a large number of food databases are needed. However, the process of analyzing nutrient intake according to individual conditions is a complex and time consuming task (KNS, 2015). CAN-Pro can be used to determine national nutritional statuses and to perform national health projects for vulnerable groups and healthcare projects for preventing and treating diseases. It can also be used to develop lunch menus and to evaluate nutritional statuses at schools and food service facilities (KNS, 2015).

CAN-Pro uses nutrient composition tables to calculate nutrient intake from consumed food. Nutrient intake is calculated by adding the amount of the food consumed by individual subjects. One function of CAN-Pro 5.0 is the ability to modify the amount of food and ingredients so to calculate the exact amount of material consumed. In addition, the ingredients contained in the food can be modified, and the user can directly add food constituents. Lao foods that are not contained in the CAN-Pro can be analyzed by editing the main database in CAN-Pro 5.0. For example, among the Lao food ingredients, coriander, mint, durian, and litchi are not included in the program. In the present study, missing foods, such as chayote, tamarind, frog, ivy ground, and lemongrass were added by using the Association of Southeast Asian Nations (ASEAN) FCT contained in the ASEAN food and nutrient database (Institute of Nutrition, Mahidol University, 2014). Food name, food group, food code, source (vegetable or animal), and nutrient values were entered directly.

The ASEAN food and nutrient database systematically compiles data from six ASEAN national FCTs (Indonesia, Malaysia, Philippines, Singapore, Thailand, and Vietnam). The first edition of the ASEAN FCT was developed in 2000, and contained 20 nutrients and energy values for about 1,740 commonly consumed foods of the 17 food groups in those countries. These data can be used for nutrition and food research in industries and communities in the ASEAN region (Puwastien, 2002; Institute of Nutrition, Mahidol University, 2014).

\section{Comparison of the food composition databases}

In the first analysis, 82 subjects were selected. A Korean and a Laotian analyst analyzed nutrient intakes of subjects using the same program (INMUCAL). Nutrient in- 
takes and the correlation coefficient for nutrient intakes of subjects calculated by the analysts were determined. In the second analysis, 79 subjects were selected. A Korean analyst analyzed food intake using both INMUCAL and CAN-Pro 5.0. In both analyses, intake of energy, carbohydrate, fat, protein (animal protein and vegetable protein), calcium ( $\mathrm{Ca}$ ), iron (Fe; animal $\mathrm{Fe}$ and vegetable $\mathrm{Fe}$ ), vitamin $\mathrm{A}$, thiamin, riboflavin, vitamin $\mathrm{C}$, and niacin were calculated.

\section{Statistical analysis}

SPSS 21.0 (IBM SPSS Statistics for Windows Version 21.0; IBM Corp., Armonk, NY, USA) was used for statistical analysis. To identify analyst-derived and programderived (INMUCAL and CAN-Pro) differences in nutrient intakes, data were expressed as mean and standard deviation, and analyzed using paired Student's $t$-tests.
Nutrient intake per 1,000 calories (nutrient density) were calculated to exclude differences in intake of the amount of food. Mean differences between the results in each analysis were calculated for each nutrient, using a 95\% confidence interval (CI). Bland \& Altman plots were constructed to check differences between values obtained from the two measurement methods and to evaluate the reliability of the two test methods. The mean percentage differences between results from the two programs and two analysts were calculated for each nutrient using a 95\% CI. For macronutrients, the differences were plotted against the means (Bland and Altman, 1986). Spearman correlation analysis was performed to estimate the correlation between nutrient intakes calculated by the two analysts and by INMUCAL and CAN-Pro. Statistical significance was set at $P<0.05$.

Table 1. Comparison of nutrient intake by Korean and Lao analysts using the INMUCAL analysis program $(\mathrm{N}=82)$

\begin{tabular}{|c|c|c|c|c|c|}
\hline & \multirow{2}{*}{ Korean analyst } & \multirow{2}{*}{ Laos analyst } & \multicolumn{2}{|c|}{ Mean difference } & \multirow{2}{*}{$P^{2)}$} \\
\hline & & & $\%$ Difference ${ }^{1)}$ & $95 \% \mathrm{CI}$ & \\
\hline Energy (kcal) & $2,416.42 \pm 935.60^{3)}$ & $2,140.40 \pm 986.13$ & 12.90 & $-42.77 ; 594.82$ & 0.089 \\
\hline Carbohydrate (g) & $\begin{array}{c}419.36 \pm 194.27 \\
(168.65 \pm 37.77)^{4)}\end{array}$ & $\begin{array}{r}366.48 \pm 207.81 \\
(165.67 \pm 37.76)\end{array}$ & $\begin{array}{l}14.43 \\
(1.80)\end{array}$ & $\begin{array}{l}-12.14 ; 117.91 \\
(-9.11 ; 15.07)\end{array}$ & $\begin{array}{l}0.110 \\
(0.625)\end{array}$ \\
\hline Fat (g) & $\begin{array}{c}36.46 \pm 26.71 \\
(16.00 \pm 12.06)\end{array}$ & $\begin{array}{c}30.03 \pm 19.12 \\
(16.04 \pm 12.20)\end{array}$ & $\begin{array}{c}21.41 \\
(-0.25)\end{array}$ & $\begin{array}{l}-0.86 ; 13.71 \\
(-3.89 ; 3.81)\end{array}$ & $\begin{array}{r}0.083 \\
(0.982)\end{array}$ \\
\hline Protein (g) & $\begin{array}{c}99.08 \pm 43.93 \\
(43.52 \pm 18.53)\end{array}$ & $\begin{array}{c}96.23 \pm 55.20 \\
(45.56 \pm 17.83)\end{array}$ & $\begin{array}{c}2.96 \\
(-4.48)\end{array}$ & $\begin{array}{l}-13.85 ; 19.54 \\
(-7.94 ; 3.86)\end{array}$ & $\begin{array}{c}0.735 \\
(0.494)\end{array}$ \\
\hline Animal protein (g) & $\begin{array}{c}54.61 \pm 36.83 \\
(25.56 \pm 20.44)\end{array}$ & $\begin{array}{c}59.28 \pm 49.07 \\
(28.77 \pm 20.57)\end{array}$ & $\begin{array}{c}7.88 \\
(-11.16)\end{array}$ & $\begin{array}{l}-18.98 ; 9.63 \\
(-9.71 ; 3.28)\end{array}$ & $\begin{array}{c}0.517 \\
(0.328)\end{array}$ \\
\hline Vegetable protein (g) & $\begin{array}{r}43.67 \pm 28.71 \\
(17.64 \pm 8.53)\end{array}$ & $\begin{array}{c}35.38 \pm 24.27 \\
(15.95 \pm 6.46)\end{array}$ & $\begin{array}{c}23.43 \\
(10.60)\end{array}$ & $\begin{array}{c}0.36 ; 16.21 \\
(-0.65 ; 4.02)\end{array}$ & $\begin{array}{r}0.041^{*} \\
(0.155)\end{array}$ \\
\hline Ca (mg) & $\begin{array}{l}483.70 \pm 1,077.00 \\
(203.62 \pm 382.48)\end{array}$ & $\begin{array}{c}465.63 \pm 511.45 \\
(239.09 \pm 229.49)\end{array}$ & $\begin{array}{c}3.88 \\
(-14.84)\end{array}$ & $\begin{array}{l}-247.35 ; 283.48 \\
(-136.28 ; 65.36)\end{array}$ & $\begin{array}{c}0.893 \\
(0.486)\end{array}$ \\
\hline $\mathrm{Fe}(\mathrm{mg})$ & $\begin{array}{l}12.27 \pm 8.73 \\
(5.49 \pm 3.77)\end{array}$ & $\begin{array}{l}13.55 \pm 9.10 \\
(6.75 \pm 4.24)\end{array}$ & $\begin{array}{c}-9.45 \\
(-18.67)\end{array}$ & $\begin{aligned}-4.15 ; & 1.60 \\
(-2.59 ; & 0.06)\end{aligned}$ & $\begin{array}{c}0.381 \\
(0.062)\end{array}$ \\
\hline Animal Fe (mg) & $\begin{array}{c}6.40 \pm 5.04 \\
(3.07 \pm 2.84)\end{array}$ & $\begin{array}{l}7.37 \pm 6.91 \\
(3.55 \pm 3.35)\end{array}$ & $\begin{array}{l}-13.16 \\
(-13.52)\end{array}$ & $\begin{array}{r}-2.91 ; 0.98 \\
(-1.48 ; 0.51)\end{array}$ & $\begin{array}{c}0.327 \\
(0.333)\end{array}$ \\
\hline Vegetable Fe (mg) & $\begin{array}{l}5.77 \pm 7.36 \\
(2.38 \pm 2.62)\end{array}$ & $\begin{array}{c}5.89 \pm 5.84 \\
(3.06 \pm 2.79)\end{array}$ & $\begin{array}{c}-2.04 \\
(-22.22)\end{array}$ & $\begin{array}{r}-2.15 ; 1.90 \\
(-1.55 ; 0.19)\end{array}$ & $\begin{array}{c}0.901 \\
(0.126)\end{array}$ \\
\hline Vitamin A ( $\mu \mathrm{g}$ RAE) & $\begin{array}{c}374.95 \pm 1185.27 \\
(171.85 \pm 433.98)\end{array}$ & $\begin{array}{c}657.09 \pm 1,537.98 \\
(320.62 \pm 723.58)\end{array}$ & $\begin{array}{l}-42.94 \\
(-46.40)\end{array}$ & $\begin{array}{l}-681.72 ; 117.45 \\
(-329.02 ; 31.48)\end{array}$ & $\begin{array}{l}0.164 \\
(0.104)\end{array}$ \\
\hline Thiamin (mg) & $\begin{array}{c}1.14 \pm 1.27 \\
(0.52 \pm 0.60)\end{array}$ & $\begin{array}{c}1.12 \pm 1.08 \\
(0.59 \pm 0.64)\end{array}$ & $\begin{array}{c}1.79 \\
(-11.86)\end{array}$ & $\begin{array}{r}-0.37 ; 0.40 \\
(-0.27 ; 0.13)\end{array}$ & $\begin{array}{c}0.927 \\
(0.463)\end{array}$ \\
\hline Riboflavin (mg) & $\begin{array}{c}1.50 \pm 3.18 \\
(0.63 \pm 1.14)\end{array}$ & $\begin{array}{l}1.25 \pm 1.09 \\
(0.62 \pm 0.49)\end{array}$ & $\begin{array}{l}20.00 \\
(1.61)\end{array}$ & $\begin{array}{r}-0.51 ; 1.00 \\
(-0.27 ; 0.29)\end{array}$ & $\begin{array}{r}0.513 \\
(0.940)\end{array}$ \\
\hline Vitamin C (mg) & $\begin{array}{c}72.35 \pm 395.08 \\
(29.46 \pm 141.51)\end{array}$ & $\begin{array}{c}71.33 \pm 108.50 \\
(38.94 \pm 57.78)\end{array}$ & $\begin{array}{c}1.43 \\
(-24.35)\end{array}$ & $\begin{array}{c}-90.47 ; 92.51 \\
(-43.82 ; 24.85)\end{array}$ & $\begin{array}{c}0.982 \\
(0.584)\end{array}$ \\
\hline Niacin (mg) & $\begin{array}{c}20.59 \pm 17.18 \\
(8.78 \pm 5.96)\end{array}$ & $\begin{array}{l}19.04 \pm 9.88 \\
(9.43 \pm 4.12)\end{array}$ & $\begin{array}{c}8.14 \\
(-6.89)\end{array}$ & $\begin{aligned} &-2.81 ; 5.92 \\
&(-2.31 ; 1.01)\end{aligned}$ & $\begin{array}{c}0.481 \\
(0.438)\end{array}$ \\
\hline
\end{tabular}

${ }^{1)}$ Percent difference between the Korean and Lao analysts using the INMUCAL analysis program [(Korean analyst-Lao analyst) $\times 100 /$ Lao analyst] based on paired data.

2) $P$-value for paired $t$-test at ${ }^{*} P<0.05$.

3) Data show mean $\pm S D$.

${ }^{4)}$ Energy and nutrient intakes per $1,000 \mathrm{kcal}$

CI, confidence interval; RAE, retinol activity equivalents. 


\section{RESULTS}

Nutrient intakes were compared by analysts from Korea and Laos to identify differences as a function of the analysts from two different countries (Table 1). Both analysts analyzed nutrient intakes of the same subjects by INMUCAL. The average calorie intake was about 2,416.42 $\pm 935.60 \mathrm{kcal}$ as calculated by the Korean analyst, and $2,140.40 \pm 986.13 \mathrm{kcal}$ as calculated by the Lao analyst. The mean difference was not significant. Intake of most nutrients, including macronutrients and micronutrients, did not significantly differ by analyst, except for vegetable protein intake, which was calculated to be significantly higher by the Korean analyst compared with the Laos analyst $(P=0.041)$. However, this difference was diminished after calculating nutrient intake per 1,000 kcal energy.

Nutrient intakes of 79 subjects calculated by the Korean researcher using the two different nutrient analysis programs (INMUCAL and CAN-Pro 5.0) are presented in
Table 2 . There were statistically significant differences in intake of several nutrients, despite analysis of the same 24-h recall survey data by the same researcher. Intake of energy $(2,487.06 \pm 1,016.73$ vs $2,486.46 \pm 947.65 \mathrm{kcal})$ and macronutrients, including carbohydrate, fat, and protein, did not different between the two programs. These results were consistent after calculating nutrient intakes per 1,000 kcal energy. Although the total protein intake was consistent between the two analysis programs, animal protein intake was lower when analyzed by CAN-Pro than INMUCAL $(35.99 \pm 26.78$ vs $55.14 \pm 37.31$ g; $P=$ 0.001). This significant difference remained after calculating animal protein intake per 1,000 kcal. Intake of vegetable protein was comparable between the two programs. However, after calculating intake of vegetable protein per $1,000 \mathrm{kcal}$, a significantly higher intake was calculated with INMUCAL than CAN-Pro $(P=0.038)$.

In addition, there were significant differences $(P=0.000)$ in the average intakes of total $\mathrm{Fe}$ and vegetable Fe calcu-

Table 2. Comparison of nutrient intake by a Korean researcher using INMUCAL and CAN-Pro 5.0 (N=79)

\begin{tabular}{|c|c|c|c|c|c|}
\hline & \multirow{2}{*}{ CAN-Pro 5.0} & \multirow{2}{*}{ INMUCAL } & \multicolumn{2}{|c|}{ Mean difference } & \multirow{2}{*}{$P^{2)}$} \\
\hline & & & $\%$ Difference $^{1)}$ & $95 \% \mathrm{CI}$ & \\
\hline Energy (kcal) & $2,487.06 \pm 1,016.73^{3)}$ & $2,486.46 \pm 947.65$ & 0.02 & $(-336.76 ; 337.97)$ & 0.997 \\
\hline Carbohydrate (g) & $\begin{array}{c}428.99 \pm 212.34 \\
(165.24 \pm 40.09)^{4)}\end{array}$ & $\begin{array}{c}436.12 \pm 197.44 \\
(170.81 \pm 38.33)\end{array}$ & $\begin{array}{l}-1.63 \\
(-3.26)\end{array}$ & $\begin{array}{c}(-76.53 ; 62.28) \\
(-18.17 ; 7.03)\end{array}$ & $\begin{array}{c}0.839 \\
(0.381)\end{array}$ \\
\hline Fat (g) & $\begin{array}{c}36.76 \pm 28.64 \\
(16.84 \pm 13.95)\end{array}$ & $\begin{array}{c}37.01 \pm 25.75 \\
(15.89 \pm 11.80)\end{array}$ & $\begin{array}{l}-0.68 \\
(5.98)\end{array}$ & $\begin{array}{l}(-8.69 ; 8.17) \\
(-3.33 ; 5.24)\end{array}$ & $\begin{array}{c}0.952 \\
(0.659)\end{array}$ \\
\hline Protein (g) & $\begin{array}{c}91.79 \pm 36.38 \\
(39.41 \pm 13.65)\end{array}$ & $\begin{array}{c}98.79 \pm 42.75 \\
(41.75 \pm 16.64)\end{array}$ & $\begin{array}{l}-7.09 \\
(-5.60)\end{array}$ & $\begin{array}{l}(-20.72 ; 6.74) \\
(-6.91 ; 2.22)\end{array}$ & $\begin{array}{c}0.314 \\
(0.310)\end{array}$ \\
\hline Animal protein (g) & $\begin{array}{c}35.99 \pm 26.78 \\
(16.61 \pm 14.16)\end{array}$ & $\begin{array}{c}55.14 \pm 37.31 \\
(24.53 \pm 19.26)\end{array}$ & $\begin{array}{l}-34.73 \\
(-32.29)\end{array}$ & $\begin{array}{l}(-29.88 ;-8.43) \\
(-13.10 ;-2.74)\end{array}$ & $\begin{array}{c}0.001^{* *} \\
\left(0.003^{* *}\right)\end{array}$ \\
\hline Vegetable protein (g) & $\begin{array}{r}39.99 \pm 21.01 \\
(15.41 \pm 4.43)\end{array}$ & $\begin{array}{l}42.90 \pm 19.55 \\
(16.95 \pm 4.53)\end{array}$ & $\begin{array}{l}-6.78 \\
(-9.09)\end{array}$ & $\begin{array}{c}(-9.75 ; 3.94) \\
(-2.98 ;-0.09)\end{array}$ & $\begin{array}{c}0.401 \\
\left(0.038^{*}\right)\end{array}$ \\
\hline Ca (mg) & $\begin{array}{c}437.48 \pm 549.96 \\
(197.20 \pm 271.38)\end{array}$ & $\begin{array}{c}377.13 \pm 238.97 \\
(159.69 \pm 96.31)\end{array}$ & $\begin{array}{l}16.00 \\
(23.49)\end{array}$ & $\begin{array}{l}(-67.52 ; 188.22) \\
(-22.33 ; 97.37)\end{array}$ & $\begin{array}{c}0.350 \\
(0.216)\end{array}$ \\
\hline $\mathrm{Fe}(\mathrm{mg})$ & $\begin{array}{c}19.97 \pm 11.98 \\
(8.15 \pm 3.66)\end{array}$ & $\begin{array}{l}11.98 \pm 7.00 \\
(5.07 \pm 2.94)\end{array}$ & $\begin{array}{c}66.69 \\
(60.75)\end{array}$ & $\begin{array}{c}(4.78 ; 11.22) \\
(2.05 ; 4.11)\end{array}$ & $\begin{array}{c}0.000^{* *} \\
\left(0.000^{* *}\right)\end{array}$ \\
\hline Animal Fe (mg) & $\begin{array}{l}4.78 \pm 6.36 \\
(2.27 \pm 3.43)\end{array}$ & $\begin{array}{l}6.62 \pm 5.64 \\
(2.92 \pm 2.67)\end{array}$ & $\begin{array}{l}-27.79 \\
(-22.26)\end{array}$ & $\begin{array}{l}(-3.77 ; 0.10) \\
(-1.56 ; 0.28)\end{array}$ & $\begin{array}{c}0.062 \\
(0.170)\end{array}$ \\
\hline Vegetable Fe (mg) & $\begin{array}{l}13.58 \pm 9.72 \\
(5.13 \pm 2.33)\end{array}$ & $\begin{array}{l}5.25 \pm 2.89 \\
(2.13 \pm 1.07)\end{array}$ & $\begin{array}{c}158.67 \\
(140.85)\end{array}$ & $\begin{array}{c}(6.01 ; 10.64) \\
(2.44 ; 3.57)\end{array}$ & $\begin{array}{c}0.000^{* *} \\
\left(0.000^{* *}\right)\end{array}$ \\
\hline Vitamin A ( $\mu \mathrm{g}$ RAE) & $\begin{array}{c}708.07 \pm 1526.44 \\
(360.74 \pm 914.74)\end{array}$ & $\begin{array}{c}375.73 \pm 1202.03 \\
(152.56 \pm 397.78)\end{array}$ & $\begin{array}{c}88.45 \\
(136.46)\end{array}$ & $\begin{array}{c}(-104.94 ; 769.62) \\
(-19.36 ; 435.72)\end{array}$ & $\begin{array}{c}0.134 \\
(0.072)\end{array}$ \\
\hline Thiamin (mg) & $\begin{array}{c}1.77 \pm 0.83 \\
(1.01 \pm 0.65)\end{array}$ & $\begin{array}{c}1.06 \pm 0.88 \\
(0.48 \pm 0.51)\end{array}$ & $\begin{array}{c}66.98 \\
(110.42)\end{array}$ & $\begin{array}{l}(0.44 ; 1.00) \\
(0.35 ; 0.73)\end{array}$ & $\begin{array}{c}0.000^{* *} \\
\left(0.000^{* *}\right)\end{array}$ \\
\hline Riboflavin (mg) & $\begin{array}{c}1.38 \pm 1.02 \\
(0.62 \pm 0.49)\end{array}$ & $\begin{array}{c}1.19 \pm 1.18 \\
(0.50 \pm 0.45)\end{array}$ & $\begin{array}{c}15.97 \\
(24.00)\end{array}$ & $\begin{array}{l}(-0.16 ; 0.54) \\
(-0.02 ; 0.26)\end{array}$ & $\begin{array}{c}0.272 \\
(0.089)\end{array}$ \\
\hline Vitamin C (mg) & $\begin{array}{r}97.86 \pm 149.22 \\
(43.61 \pm 58.82)\end{array}$ & $\begin{array}{c}29.91 \pm 59.28 \\
(13.80 \pm 30.84)\end{array}$ & $\begin{array}{c}227.18 \\
(216.01)\end{array}$ & $\begin{array}{l}(32.46 ； 103.45) \\
(15.63 ; 44.01)\end{array}$ & $\begin{array}{c}0.000^{* *} \\
\left(0.000^{* *}\right)\end{array}$ \\
\hline Niacin (mg) & $\begin{array}{c}20.60 \pm 9.63 \\
(8.78 \pm 3.19)\end{array}$ & $\begin{array}{c}19.42 \pm 10.43 \\
(8.08 \pm 3.40)\end{array}$ & $\begin{array}{c}6.08 \\
(8.66)\end{array}$ & $\begin{array}{l}(-2.20 ; 4.56) \\
(-0.40 ; 1.79)\end{array}$ & $\begin{array}{c}0.489 \\
(0.207)\end{array}$ \\
\hline
\end{tabular}

${ }^{1)}$ Percent difference between CAN Pro 5.0 and INMUCAL program [(CAN Pro-INMUCAL) $\times 100 /$ INMUCAL] based on paired data.

2) $P$-value for paired $t$-test at ${ }^{*} P<0.05$ and ${ }^{* *} P<0.01$.

${ }^{3)}$ Data show mean $\pm S D$.

${ }^{4)}$ Energy and nutrient intakes per 1,000 kcal.

CI, confidence interval; RAE, retinol activity equivalents. 
Table 3. Comparison of coefficients of variation by Korean and Lao analysts using INMUCAL analysis program

\begin{tabular}{lcc}
\hline & \multicolumn{2}{c}{$\mathrm{CV}^{1)}$} \\
\cline { 2 - 3 } & Korean analyst & Laos analyst \\
\hline Energy (kcal) & 0.38 & 0.46 \\
Carbohydrate (g) & 0.46 & 0.56 \\
Fat (g) & 0.73 & 0.63 \\
Protein (g) & 0.44 & 0.57 \\
Animal protein (g) & 0.67 & 0.82 \\
Vegetable protein (g) & 0.65 & 0.68 \\
Ca (mg) & 2.21 & 1.09 \\
Fe (mg) & 0.71 & 0.67 \\
Animal Fe (mg) & 0.78 & 0.93 \\
Vegetable Fe (mg) & 1.27 & 0.98 \\
Vitamin A ( $\mu$ g RAE) & 3.14 & 2.33 \\
Thiamin (mg) & 1.11 & 0.95 \\
Riboflavin (mg) & 2.11 & 0.87 \\
Vitamin C (mg) & 5.43 & 1.51 \\
Niacin (mg) & 0.83 & 0.52 \\
\hline
\end{tabular}

${ }^{1)}$ Between person coefficient of variation.

$R A E$, retinol activity equivalents.

lated by the two programs, even after adjusting for energy intake $(P=0.000)$. Although intake of animal Fe was similar between the two programs, intake of vegetable $\mathrm{Fe}$ was calculated to be $8.33 \mathrm{mg}$ higher by CAN-Pro $(P=$ 0.000). Furthermore, thiamin intake was calculated to be
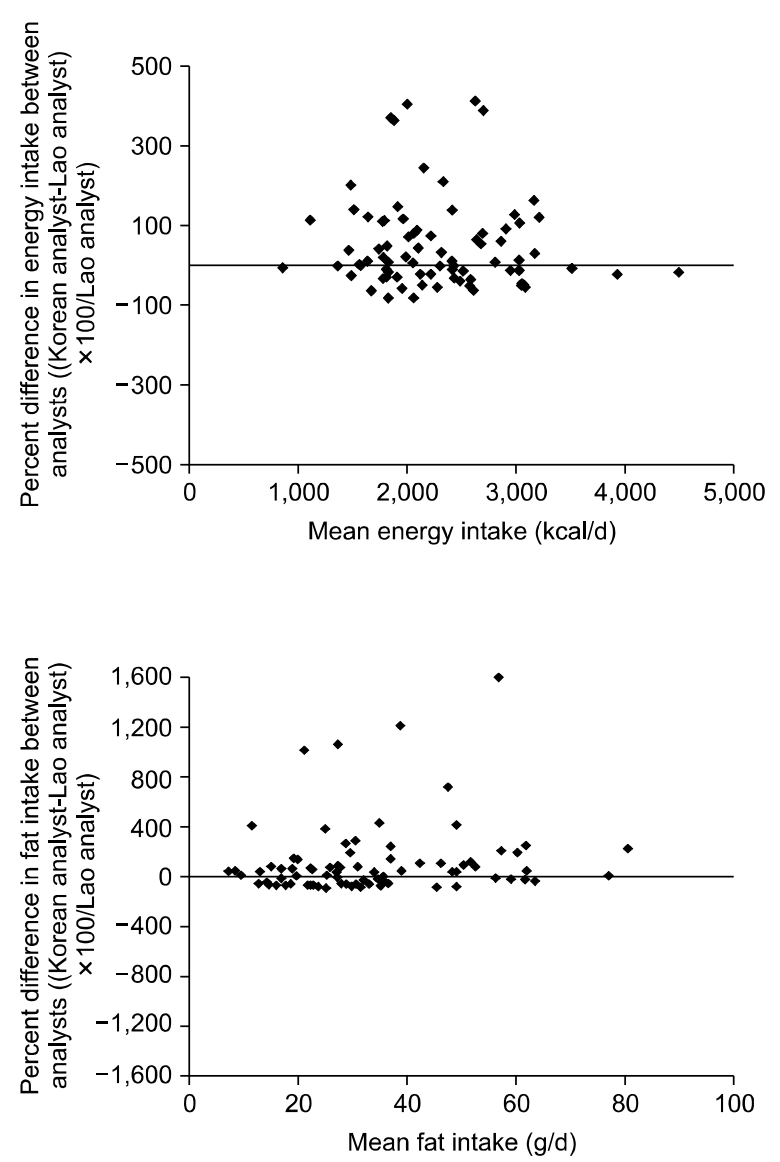

higher by CAN-Pro than INMUCAL $(P=0.000)$, regardless of adjusting for total energy intake. In addition, vitamin $C$ intake was approximately 2.3 times higher by CAN-Pro $(P=0.000)$. The differences in nutrient intake between the two programs varied from $0.02 \%$ to $227.18 \%$, depending on the nutrient.

To ascertain whether differences in calculated intake are caused by the analyst or program, the coefficients of variation were compared. No nutrient intake values showed significant correlations between the two analysts or the two programs (data not shown). The betweenperson coefficient variation of mean and standard deviation values analyzed by the two analysts using INMUCAL is shown in Table 3. The between-person coefficient variation for the Korean analyst was $0.38 \sim 5.43$, with the highest coefficient of variation observed for vitamin $\mathrm{C}$ (5.43), followed by vitamin A (3.14), and lowest for energy (0.38). However, the between-person coefficient variation for the Laos analyst was $0.46 \sim 2.33$, with the highest coefficient of variation observed for vitamin A (2.33), followed by vitamin $\mathrm{C}$, and the lowest for energy (0.46). Both analysts showed consistent results in that highest between-person coefficients of variation were observed for vitamins $\mathrm{A}$ and $\mathrm{C}$, and the lowest between-person coefficients of variation were observed for energy. Although the mean intake of nutrients were different between the
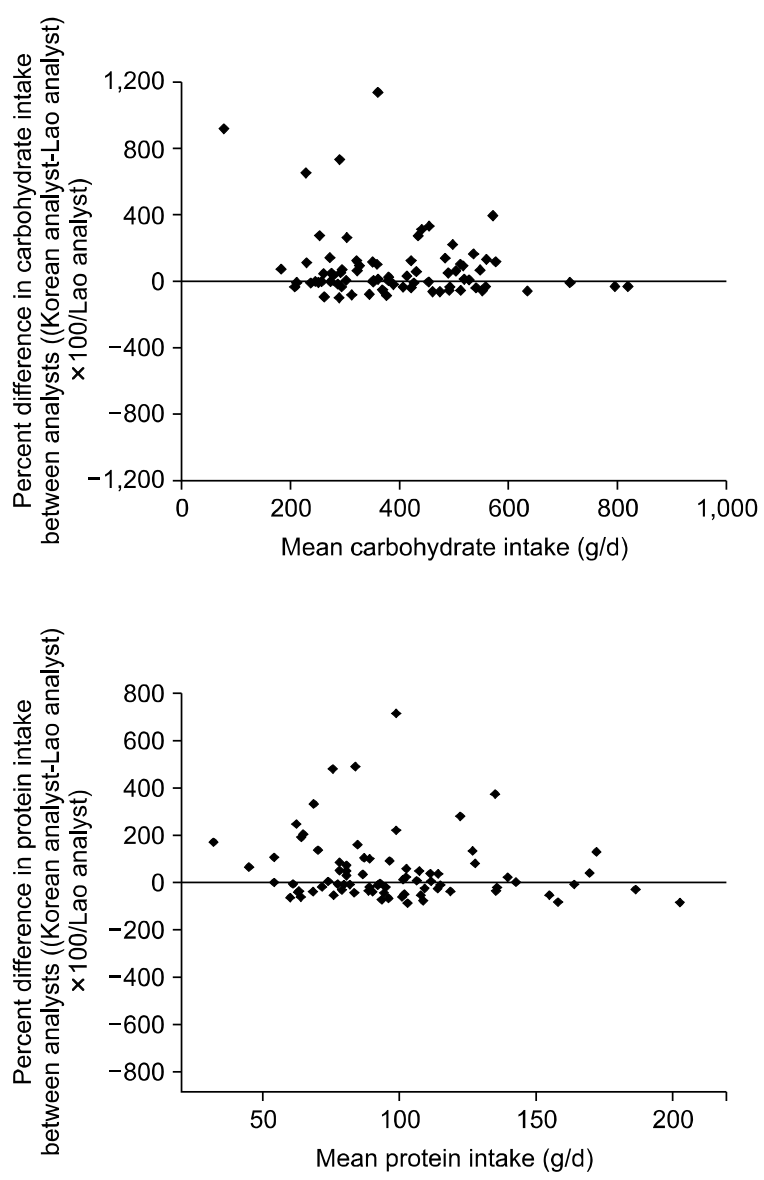

Fig. 1. Plot of the percent difference in intake based on data from the Korean and Lao analysts against mean intake. 

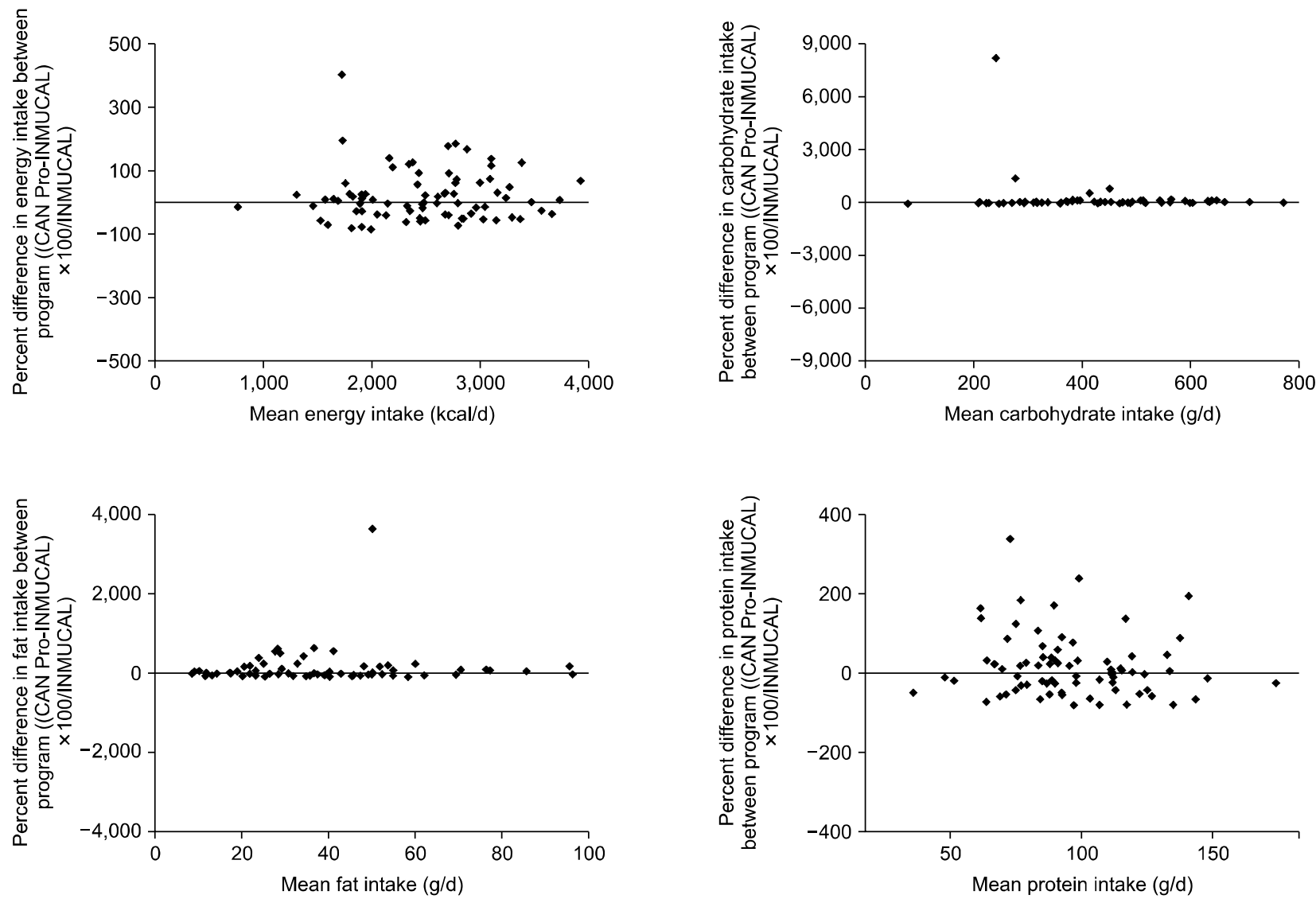

Fig. 2. Plot of the percent difference intake based on data from the CAN-Pro and INMUCAL analysis programs against mean intake.

analysts, the between-person coefficients of variation of some micronutrients was large, suggesting the large differences between individual intakes.

The mean intakes and consumption of macronutrients determined by the different analysts were compared for 82 subjects. If the results greatly differ, the two methods may have large errors. For these subjects, although the mean intakes of carbohydrate and fat were within the error ranges (Fig. 1), the errors of differences in protein intake were much larger. In addition, mean differences in carbohydrate and fat intakes were small between the two programs. However, although the mean differences in protein intake tended to have a larger error than those of other macronutrients, these differences were within the error range, indicating high reliability of the results (Fig. 2).

\section{DISCUSSION}

In this study, the nutritional intake of Laotians was analyzed by analysists from Lao and Korea using INMUCAL. In addition, two nutritional analysis programs, the Thailand nutritional analysis program (INMUCAL) and the Korean nutritional analysis program (CAN-Pro), were used by a single analyst to understand the nutritional status in Laos and to identify an appropriate nutritional analysis program. There no significant difference in nutrient intake were reported by the two analysts, however there was a significant difference in micronutrient intake calculated by the two programs. The nutrients that showed the greatest individual differences were mainly micronutrients. In particular, consumption of dairy products and fruit was low in Laos.

Intake of nutrients calculated by INMUCAL did not differ between the two analysts, with the exception of vegetable protein, which may be explained by application of the same program without adding extra food composition data. However, INMUCAL is a nutrient analysis program for Thailand, not Laos. Although neighboring countries have similar food cultures, cooking method or recipes in each country are different (Kim et al., 2013). Therefore, Thai foods and recipes may differ with from those in Lao. Therefore, development of a nutrition analysis program that includes national food databases and standardized recipes is pivotal for evaluating the nutritional status of people in a certain country. In addition, accurate nutritional analysis is difficult because of different analysis techniques of different analysts. Therefore, to manage the program proficiently by an analyst, a prior knowledge of the built-in databases and recipes is important (Jung et al., 2013). It is necessary to understand 
the structure and contents of the database in the program; this knowledge improves the accuracy of the nutritional analysis of the nutritional status of that country.

There were significant differences in nutrient intake determined by the same analyst using the two analysis programs (INMUCAL and CAN-Pro), particularly regarding micronutrient intake. Of the micronutrients, intakes of $\mathrm{Fe}$, thiamin, and vitamin $\mathrm{C}$ were calculated to be higher by CAN-Pro than INMUCAL. By contrast, calculated intakes of carbohydrate, protein, and fat did not significantly differ between the two programs. Rice is a main staple food in the traditional Korean diet (Kim et al., 2012), and rice noodles and steamed glutinous rice (sticky rice) are major dishes of Laotian (Barennes et al., 2009); this is similar to the food culture of other Asian countries, including Thailand.

The calculated thiamine intake significantly differed between the software programs. Cereals grains are rich in thiamine (MOHW and KNS, 2016); however, the consumption and kind of rice differs between different countries (Taleon et al., 2020). Although rice dishes may be similar between countries, the types and nutrient contents of rice varieties vary. For example, in Korea individuals consume refined rice instead of glutinous rice, and wheat flour noodles instead of rice noodles. In addition, nutrient composition (e.g. Fe, thiamine, $\mathrm{Ca}$, and riboflavin) of glutinous rice (raw) in Korean Standard FCT provided by the Korean Rural Development Administration differs from the nutrient content of sticky rice (raw) listed by the ASEAN FCT. The absence of a built-in database or other database of other micronutrients may also cause this difference.

CAN-Pro does not contain information on food compositions of specific local fruits and vegetables, such as lemongrass, durian, tamarind, and chayote. Thus, the ASEAN FCT was used to determine the composition of these foods (Institute of Nutrition, Mahidol University, 2014), which could have contributed to the different micronutrient intakes of the two programs. The Korean nutritional analysis program does not contain a database or standardized recipes for Lao food, which makes it difficult to apply CAN-Pro directly to Lao food. Nutrient databases are primary tools for calculating nutrient intake from dietary intake surveys. In general, the amounts of foods and nutrients consumed by each subject can be calculated differently depending on the content of the nutrient database (Shim and Paik, 2009). For example, food intake from the Baltic nutrition survey conducted in Estonia, Latvia, and Lithuania in 1997 were analyzed separately using the Russian Institute of Nutrition Food Composition Database (Russian database) and the Finnish Micro-Nutrica Analysis program (Estonia) (Vaask et al., 2004). The Russian database provided significantly higher intakes for most nutrients, including energy, protein, fat, carbohydrate, $\mathrm{Ca}$, and $\mathrm{Fe}$, compared with the Estonian database. In another study, 130 college students in Cheongju, Korea were interviewed on three consecutive days for a 24-h recall method, and nutrient intake was calculated using the 6th and 7th revised nutrient databases of the Recommended Dietary Allowances for Koreans (Hyun and Han, 2001). Most of the nutrient intake analyzed by the 7 th version of the database, were lower than those analyzed by the 6th version of the database, with the exception of vitamin A and folic acid. These results indicated the importance of nutrient databases for analyzing individual nutrient intake. Therefore, it is necessary to construct a tailored food database specific to each country by considering regional differences, to improve the accuracy of analyzing intake of both macronutrients and micronutrients.

In order to examine nutritional statuses, data obtained from INMUCAL by two analyst was compared to the Committee on Thai DRI (2003) (data not shown). DRI values in Thailand recommend daily consumption of 2,100 2,150 and 1,750 kcal for men and women aged $19 \sim 70$ years, respectively. In the present study, energy intake was slightly higher than the recommended DRI in Thailand. Furthermore, protein intake recommendations are $57 \mathrm{~g}$ for adult men and $52 \mathrm{~g}$ for adult women; the subjects in the current study consumed sufficient $(\geq 90 \mathrm{~g})$ amount of protein, as based on the DRI for Thais. For Ca, both men and women are recommended to consume 800 mg per day; however, the Ca intake (about $400 \mathrm{mg}$ ) was much lower than the recommended values. Fe intake is recommended at $10.4 \mathrm{mg}$ for men and $24.7 \mathrm{mg}$ for women; however, the two analysts reported values of $12 \sim 13$ $\mathrm{mg}$. For thiamine and riboflavin, mean intakes were close to recommended values. However, intake of vitamin C was much lower for study subjects (72.35 mg and 71.33 $\mathrm{mg}$, as analyzed by the Korean and Laos analysts, respectively) compared with the DRI in Thailand (90 mg for adult men and $75 \mathrm{mg}$ for adult women). The differences in nutrient intake calculated by the two analysts using the same software ranged from $0.25 \%$ (fat) to $46.40 \%$ (vitamin A) after adjusting for energy consumption. Differences in absolute values of nutrient intake (carbohydrate, fat, protein, riboflavin, and niacin) were within $10 \%$, whereas corresponding differences between $\mathrm{Ca}, \mathrm{Fe}$, vitamin $\mathrm{A}$, thiamin, and vitamin $\mathrm{C}$ intakes were $10 \sim 50 \%$.

The correlation between the analysts or software programs for nutrient intake was not significant (data not shown). These correlation coefficients can be affected by study subjects (Delcourt et al., 1994). To avoid extreme food intake errors, subjects who consumed $\leq 500$ and $\geq 5,000$ kcal energy were excluded. However, because subjects who consumed an extreme amount of specific nutrients other than energy were included, intake varia- 
tion was large for each individual, which might be a cause of the large variation and the lack of a significant correlation coefficient. In general, correlation coefficients depends on precision of the method (Delcourt et al., 1994). In the present study, the lack of a significant correlation coefficient could be because of different databases and analysts. Thus, it is critical to establish a consistent and specific food composition database according to the nutritional circumstances and needs in each country (Puwastien, 2002).

Differences in mean carbohydrate intake between individuals was not considerable, irrespective of the analyst, whereas large differences existed between the intakes of vitamins $\mathrm{A}$ and $\mathrm{C}$ and energy showed the smallest coefficient of variation. Between person variation refers to differences in intake among individuals, which may be affected by individuals who consume specific foods much more than others. A large difference between the average nutrient intake of the group and the distribution of nutrient intake indicates large between-personal variation (Lee et al., 2010). Therefore, it is necessary to accurately understand the nutritional status of vitamin intakes of adults in Laos given that between-personal variation of vitamins is higher than that of macronutrients. Intake of vitamins $\mathrm{A}$ and $\mathrm{C}$ either above or below the recommended level of dietary intake can exert unfavorable side effects (Evans and Lacey, 1986), so it is important to appropriate nutritional education based on accurate analysis of nutritional status.

In addition, we checked food group intake directly using the 24-h recall survey sheet. The 24-h recall survey results showed that most subjects had a high vitamin A intake from papaya salad and vegetables. In addition, cabbage, guava, cherry, banana, bamboo shoot, morning glory, and vegetables were highly consumed by subjects with a high intake of vitamin C. Subjects who consumed mainly rice and fish, and who consumed a low amount of fruit and vegetables had insufficient intake of vitamins $\mathrm{A}$ and $\mathrm{C}$. Individual differences in intake of vitamins A and $\mathrm{C}$ were high. Reasons for insufficient vitamin $\mathrm{C}$ intake include over-cooking and low intake of fresh fruit and vegetables. Therefore, developing countries require comprehensive nutritional education about adequate intake, hypervitaminosis, deficiency, and methods of intake of vitamins and minerals (Khan and Iqbal, 2006; Akhtar et al., 2013).

The error of the difference in consumption of macronutrients determined by the different analysts was slightly larger compared with that between the two programs. This may be caused by analysis methods used by the analysts or their understanding of the recipes. When entering and analyzing Lao food through the Thailand program, the Lao analyst should be more familiar with the foods and able to substitute similar food than the Korean analyst.

We evaluated the nutritional status of Lao subjects through data obtained using INMUCAL by two analysts according to the Thai DRI. The proportion of consumed macronutrients consisting of carbohydrate was $76 \%$ and $74 \%$ as calculated by the Korean and Lao analysts, respectively. Low carbohydrate intake decreases body weight and improves certain risk factors for coronary heart disease (Foster et al., 2003). In the current study, protein intake was sufficient to meet the Thai DRI, whereas the Ca intake was insufficient. Sedentary workers in Thailand have been reported to have a higher intake of protein and a lower intake of Ca compared with the Thai DRI. Inadequate intake of vitamin $\mathrm{C}$ is also due to a lack of fruit and vegetables consumption in Thailand, which is consistent with our results (Ivanovitch et al., 2014).

In addition, we directly evaluated intake of different food groups through the 24-h recall survey sheet. The results showed that $90 \%$ of subjects did not consume dairy products, and $54 \%$ of subjects did not consume fruit. Dairy products are major sources of $\mathrm{Ca}$, as well as other vitamins and minerals, including phosphorus, magnesium, zinc, iodine, potassium, vitamin A, vitamin D, vitamin B12, and riboflavin (Dror and Allen, 2014). Insufficient intake of dairy products and fruit can cause insufficient intake of $\mathrm{Ca}$ and micronutrients, and contribute to the inadequate nutrition levels of developing countries (Allen, 2003; Díaz et al., 2003; Ramakrishnan, 2003; Müller and Krawinkel, 2005). Consistent with our results, a recent study using INMUCAL on the nutritional status of individuals of all ages in Laos revealed that vitamin A, vitamin B, vitamin C, and micronutrients, including $\mathrm{Ca}$ and $\mathrm{Fe}$, are inadequately ingested (Ratsavong et al., 2020).

The major limitations of this study are the small sample size with the short duration of the dietary survey (only 1 day in Vientiane, Laos), which makes it difficult to apply the findings to the general public. Analyzing data obtained from a large number of subjects with several days of dietary interviews would provide more reliable information to understand nutritional intake. Furthermore, there is a lack of statistical results of food group intake since this could not be confirmed using the INMUCAL program. Instead, food group intake was checked through the 24-h recall survey sheet, which highlighted the importance of nutrition analysis programs that can analyze both food groups and nutrients. In addition, regular program updates are necessary to understand appropriate food and nutrient intakes. A strength of this study is that it assessed nutritional status using both a Thai nutrition program with similar recipes as Laos and the Korean CAN-Pro. Therefore, these results are valuable for understanding the nutrition status in Lao PDR despite the absence of its own nutrient analysis program. 
In conclusion, nutritional intake was analyzed using a the 24-h recall method. However, differences exist between nutritional databases, which emphasize the need for more research on the development of accurate and comprehensive databases that represent regional food consumption. Since Asian diets have become more westernized and urbanized, it is necessary to develop up-todate national nutritional databases and programs to understand current nutritional statuses and perform appropriate nutritional educational and counseling in Laos.

\section{ACKNOWLEDGEMENTS}

The funders have no role in study design, data collection, analysis, interpretation, and manuscript preparation. All authors appreciate Dr. Somsori Charoenkiatkul at Mahidol University in Thailand for her help to obtain INMUCAL program. This work was supported by the Korea International Cooperation Agency (KOICA) under the No. 2016-105-1.

\section{AUTHOR DISCLOSURE STATEMENT}

The authors declare no conflict of interest.

\section{REFERENCES}

Akhtar S, Ahmed A, Randhawa MA, Atukorala S, Arlappa N, Ismail $\mathrm{T}$, et al. Prevalence of vitamin A deficiency in South Asia: causes, outcomes, and possible remedies. J Health Popul Nutr. 2013. 31:413-423.

Allen LH. Interventions for micronutrient deficiency control in developing countries: past, present and future. J Nutr. 2003. 133:3875S-3878S.

Banjong O, Menefee A, Sranacharoenpong K, Chittchang U, Egkantrong P, Boonpraderm A, et al. Dietary assessment of refugees living in camps: a case study of Mae La Camp, Thailand. Food Nutr Bull. 2003. 24:360-367.

Barennes H, Simmala C, Odermatt P, Thaybouavone T, Vallee J, Martinez-Aussel B, et al. Postpartum traditions and nutrition practices among urban Lao women and their infants in Vientiane, Lao PDR. Eur J Clin Nutr. 2009. 63:323-331.

Bland JM, Altman DG. Statistical methods for assessing agreement between two methods of clinical measurement. Lancet. 1986. 1:307-310.

Bramwell L, Mortimer D, Rose M, Fernandes A, Harrad S, PlessMulloli T. UK dietary exposure to PCDD/Fs, PCBs, PBDD/Fs, PBBs and PBDEs: comparison of results from 24-h duplicate diets and total diet studies. Food Addit Contam Part A Chem Anal Control Expo Risk Assess. 2017. 34:65-77.

Committee on Thai DRI. Dietary reference intake for Thais 2003. Ministry of Public Health, Bangkok, Thailand. 2003.

Delcourt C, Cubeau J, Balkau B, Papoz L. Limitations of the correlation coefficient in the validation of diet assessment methods. CODIAB-INSERM-ZENECA Pharma Study Group. Epidemiology. 1994. 5:518-524.

Díaz JR, de las Cagigas A, Rodríguez R. Micronutrient deficiencies in developing and affluent countries. Eur J Clin Nutr. 2003. 57: S70-S72.

Dror DK, Allen LH. Dairy product intake in children and adolescents in developed countries: trends, nutritional contribution, and a review of association with health outcomes. Nutr Rev. 2014. 72:68-81.

Evans CD, Lacey JH. Toxicity of vitamins: complications of a health movement. Br Med J. 1986. 292:509-510.

Foster GD, Wyatt HR, Hill JO, McGuckin BG, Brill C, Mohammed $\mathrm{BS}$, et al. A randomized trial of a low-carbohydrate diet for obesity. N Engl J Med. 2003. 348:2082-2090.

Han JS, Rhee SH. Computerized system for assessing nutrients from food groups. J Korean Soc Food Nutr. 1993. 22:559-564.

Holben DH, Marshall MB. Position of the academy of nutrition and dietetics: food insecurity in the United States. J Acad Nutr Diet. 2017. 117:1991-2002.

Hyun T, Han YH. Comparison of folate intake and food sources in college students using the 6 th vs. 7 th nutrient database. Korean J Nutr. 2001. 34:797-808.

Institute of Nutrition, Mahidol University. ASEAN Food Composition Database 2014. 2014 [cited 2020 Mar 20]. Available from: http://www.inmu.mahidol.ac.th/aseanfoods/composi tion_data.html

Institute of Nutrition, Mahidol University. Manual of INMUCALnutrients V.3 program for nutritional calculation. 2013 [cited 2020 Mar 20]. Available from: http://www.inmu.mahidol.ac. th/inmucal/

Ivanovitch K, Klaewkla J, Chongsuwat R, Viwatwongkasem C, Kitvorapat W. The intake of energy and selected nutrients by thai urban sedentary workers: an evaluation of adherence to dietary recommendations. J Nutr Metab. 2014. 2014:145182. https://doi.org/10.1155/2014/145182

Jeharsae R, Sangthong R, Chongsuvivatwong V. Dual dietary intake problems among under-five years old children living in an armed conflict area of southern Thailand. J Med Assoc Thai. 2011. 94:1104-1108.

Jung HJ, Lee SE, Kim D, Noh H, Song S, Kang M, et al. Development and feasibility of a web-based program 'Diet Evaluation System (DES)' in urban and community nutrition survey in Korea. Korean J Health Promot. 2013. 13:107-115.

Khan RM, Iqbal MP. Deficiency of vitamin C in south Asia. Pak J Med Sci. 2006. 22:347-355.

Kim J, Jo I, Joung H. A rice-based traditional dietary pattern is associated with obesity in Korean adults. J Acad Nutr Diet. 2012. 112:246-253.

Kim J, Lee JY, Han Y, Ahn K. Significance of Ara h 2 in clinical reactivity and effect of cooking methods on allergenicity. Ann Allergy Asthma Immunol. 2013. 110:34-38.

Kim JY, Yi K, Kang M, Kang Y, Lee G, Kim HHS, et al. Comparison of dietary behavior, changes of diet, and food intake between $40 \sim 59$ years old subjects living in urban and rural areas in Lao PDR. J Nutr Health. 2016. 49:111-124.

Klunklin S, Channoonmuang K. Snack consumption in normal and undernourished preschool children in Northeastern Thailand. J Med Assoc Thai. 2006. 89:706-713.

KNS. Computer aided nutritional analysis program 5.0 (web ver.). The Korean Nutrition Society, Seoul, Korea. 2015 [cited 2020 Mar 20]. Available from: http://canpro5.kns.or.kr/

Lee JE, Kim JH, Jung IK. Development of a semi-quantitative food frequency questionnaire for assessing the usual dietary intake of Korean adolescents. J Korean Home Econ Assoc. 2010. 48: 121-134.

Low WY, Lee YK, Samy AL. Non-communicable diseases in the Asia-Pacific region: prevalence, risk factors and communitybased prevention. Int J Occup Med Environ Health. 2015. 28: 20-26.

MOHW and KNS. Dietary reference intakds for Koreans 2015. 
Ministry of Health and Welfare, Sejong, Korea. The Korean Nutrition Society, Seoul, Korea. 2016 [cited 2020 Oct 13]. Available from: http://www.mohw.go.kr/react/jb/sjb030301 vw.jsp?PAR_MENU_ID $=03 \& M E N U \_I D=032901 \& C O N T$ SEQ $=337356$ \&page $=1$

Müller O, Krawinkel M. Malnutrition and health in developing countries. CMAJ. 2005. 173:279-286.

Pingali P. Westernization of Asian diets and the transformation of food systems: implications for research and policy. Food Policy. 2007. 32:281-298.

Puwastien P. Issues in the development and use of food composition databases. Public Health Nutr. 2002. 5:991-999.

Ramakrishnan U. Prevalence of micronutrient malnutrition worldwide. Nutr Rev. 2002. 60:S46-S52.

Ratsavong K, van Elsacker T, Doungvichit D, Siengsounthone L, Kounnavong S, Essink D. Are dietary intake and nutritional status influenced by gender? The pattern of dietary intake in Lao PDR: a developing country. Nutr J. 2020. 19:31. https://doi. org/10.1186/s12937-020-00545-9

Schoendorfer N, Gannaway D, Jukic K, Ulep R, Schafer J. Future doctors' perceptions about incorporating nutrition into standard care practice. J Am Coll Nutr. 2017. 36:565-571.

Shim JS, Lee JS, Kim KN, Lee HS, Kim HY, Chang MJ. Selection of key foods for the systematic management of a food and nu- trient composition database. Nutr Res Pract. 2017. 11:500506.

Shim YJ, Paik HY. Reanalysis of 2007 Korean National Health and Nutrition Examination Survey (2007 KNHANES) results by CAN-Pro 3.0 nutrient database. Korean J Nutr. 2009. 42: 577-595.

Supasyndh O, Satirapoj B, Seenamngoen S, Yongsiri S, Choovichian P, Vanichakarn S. Nutritional status of twice and thrice-weekly hemodialysis patients with weekly Kt/V > 3.6. J Med Assoc Thai. 2009. 92:624-631.

Taleon V, Gallego S, Orozco JC, Grenier C. Retention of Zn, Fe and phytic acid in parboiled biofortified and non-biofortified rice. Food Chem X. 2020. 8:100105. https://doi.org/10.1016/ j.fochx.2020.100105

Vaask S, Pomerleau J, Pudule I, Grinberga D, Abaravicius A, Robertson A, et al. Comparison of the micro-nutrica nutritional analysis program and the Russian food composition database using data from the baltic nutrition surveys. Eur J Clin Nutr. 2004. 58:573-579.

WHO. Noncommunicable diseases country profiles 2014. World Health Organization, Geneva, Switzerland. 2014 [cited 2020 Mar 20] Available from: https://www.who.int/nmh/publica tions/ncd-profiles-2014/en/ 